\title{
Medya Içeriklerinin Islamofobik Olarak Değerlendirilme Kriterleri: farkindayiz.gov.tr
}

DOI: 10.26466/opus.587279

\author{
* \\ $\underline{\text { Sefer Darıc1 }}^{*}$ - Zafer Özdemir ${ }^{* *}$ \\ * Dr. Ö̈ğr. Üyesi, Sivas Cumhuriyet Üniversitesi Sivas / Türkiye \\ E-Posta: sdarici@cumhuriyet.edu.tr \\ ORCID: 0000-0002-3630-4511 \\ ** Dr. .Öğr. Üyesi, Beykoz Üniversitesi İstanbul / Türkiye \\ E-Posta: zaferozdemir@beykoz.edu.tr \\ ORCID: 0000-0003-0398-4378
}

$\ddot{O} z$

İslamofobi ile ilgili literatürde artan bir ilgi bulunmaktadır. Türk hükümeti tarafindan Haziran 2018'de Islamofobi ile mücadele edilmesi amacıla bir veri tabanı kurulmuştur. Hollywood filmlerinden, çizgi filmlere, dijital oyunlardan, müziklere kadar tespit edilen birçok islamofobik içerik, "farkindayiz.gov.tr"adlı resmi internet adresi üzerinden erişime açılmıştır. İnternet sitesinde, halka yönelik olarak, islamofobik içeriklere karşı mücadele edilmesini ve fark ettikleri içerikleri bildirmelerini isteyen bir de çağr metni eklenmiştir. Site, çoğunlukla Müslümanların yaşadığı laik bir ülke olan Türkiye'de, islamofobi ile ilgili devletin medya içeriklerine yaklaşımını göstermesi açısından herkese açık, resmi bir kanıt sunmaktadır. Bu çalışmada medya içeriklerinin islamofobik olarak nitelendirilmesi için Türkiye'de devletin hangi kriterleri aradığı sorusu bu internet sitesi üzerinden araştırılmıştır. İç içe geçmiş tek durum deseni kullanılan bu araştırmada, sitede yer alan fotoğraf, video ve açıklamalar karşılaştırmalı içerik analizine tabi tutulmuştur. Sonuç olarak medya içeriklerinin islamofobik olarak değerlendirme kriterleri 3 ana tema altında toplanmıştır: 1- İslami sembollere saldırı. 2- Allah'a, Peygamber Muhammed'e, Kur'an-ı Kerim'e hakaret. 3-İslam-Terör ilişkilendirmesi.

Anahtar Kelimeler: İslamofobi, Popüler Kültür, İçerik Analizi , Terör 


\title{
Criteria For Evaluating Media Contents As Islamophobic: farkindayiz.gov.tr
}

\begin{abstract}
There is increasing interest in the literature on Islamophobia. A database was established by the Turkish government in June 2018 to combat Islamophobia. A lot of content that is found to be Islamophobic, from Hollywood movies to cartoons, from digital games to music, has been accessed via the official internet address "farkindayiz.gov.tr". On the website, a call text has been added to the public asking them to fight against islamophobic content and to report the content they noticed. Website created a perfect resource which is open to anyone who wants to learn the government approach of the to islamophobic criteria in to be secular country Turkey where is mostly inhabited by Muslims.In this study, the question of what criteria according to the government in Turkey were accepted to be Islamophobic media content was investigated through this website. In this research, which used a single intertwined case pattern, the photographs, videos, and descriptions on the website were subjected to comparative content analysis. The results that criteria for evaluating media contents as islamophobic are grouped into three main themes: 1 - Attack on Islamic symbols. 2-Insulting Allah, the Prophet Muhammed, and the Holy Quran. 3-To associate Islam with Terrorism
\end{abstract}

Keywords: Islamophobia, Popular culture, Content analysis, Terror 


\section{Giriş}

İslamofobi derin tarihsel kökleri olan bir kavramdır (Lean ve Esposito, 2012). Akademik literatürde Edvard Said'in (1979) “Orientalism" isimli eseriyle İslamofobiye akademik farkındalık başlamıştır (Haddad ve Harb, 2014). Bugün bu kavramın anlamı, kökleri üzerine literatürde geniş tartışmalar bulunmaktadır (Said, 1985; Vakil, 2008, 2009; Zebiri, 2008; Kayaoğlu, 2012; Meer, 2014; Kalmar ve Ramadan, 2016; Beydoun, 2016; Trein, 2017). İslamofobi'nin özellikle 9/11 saldırılarının ardından daha belirgin bir hal aldığı söylenebilir (Keyman 2002, s.16-17; Sheehi, 2011).

İslamofobi ile ilgili tartışmaların oluşmasında ve yayılmasında medyanın da payı büyüktür. Birçok araştırmada farklı ülkelerde islamofobinin medyada nasıl temsil edildiği ve medyanın yaklaşımını araştıılmıştır (Allen, 2001; Cere, 2002; Perry ve Poynting, 2006; Saeed, 2007; Gökçe, 2012; Zaal, 2012; Ansari, 2012; Awan, 2014; Ogan vd., 2014; Luqiu ve Yang, 2018). Medyanın İslami sembolleri, yaşam tarzını, doğu ile batının farklılığını sunuş şekli önemlidir. Çünkü medya kültür endüstrisinin başat aktörüdür. Medyanın; film, dizi, oyunlar ve diğer araçlarılla yarattığı popüler kültür ikonları İslamofobiyi daha geniş kitlelere yaymakta ve zihinlere kazımaktadır.

İslamofobi tartışmaları arasında Türkiye gerek coğrafi konumu ve gerekse devlet yapısı nedeniyle özel bir öneme sahiptir. Avrupa ve Asya'nın birleştiği noktada bulunan Türkiye laik bir devlettir. İslami kanunlara (Şeriat) göre yönetilmeyen ve toplumun çoğunluğunun müslümanlardan oluştuğu Türkiye, hem coğrafyave kültürel anlayış ve hem de bakış açısı bakımından adeta bir "köprü" durumundadır.

Kurucu önder Mustafa Kemal Atatürk'ün 29 Ekim 1923'te Türkiye devletinin yönetim şeklini "Cumhuriyet" olarak ilanı ve devamında gerçekleşen devrimler, sadece devlet yapısını değil toplumun İslamı yaşama pratiklerini ve zihin yapısını da değiştirmiştir. Bu açıdan Türkiye'nin İslamofobiyi nasıl değerlendirdiği ve islamofobiye nasıl yaklaştığı çok önemlidir. Bu çalışma bu açıdan da literatürdeki eksikliği gidermeye katkı sağlamaktadır.

Haziran 2018'de Türk Hükümetinin Gençlik ve Spor Bakanlığı tarafından ilk defa islamofobi ile mücadele kapsamında bir veri tabanı kurulmuştur. Hollywood filmleri, çizgi filmler, dijital oyunlar ve müzikler, islamofobik unsurlar taşıyıp, taşımadıkları açısından incelenmiştir. İslamofobik içerik taşıdığ 1 tespit edilenler "farkindayiz.gov.tr" adlı resmi internet adresi üzerinden 
erişime açılmıştır. Ayrıca sitede, halka islamofobik içeriklere karşı mücadele edilmesini ve fark ettikleri içerikleri bildirmelerini isteyen bir de çağrı metni eklenmiştir.

Resmi internet sitesi, "çoğunlukla Müslümanların yaşadığı laik bir devlet olan Türkiye'de, medya içeriklerinin hükümet tarafından islamofobik olarak değerlendirme kriterlerinin ne olduğu?" şeklindeki sorumuza resmi bir kanıt ve araştırma açısından mükemmel bir kaynak oluşturmuştur.

\section{Kültür Endüstrisi, Popüler Kültür ve İslamofobi}

Medya insanları ve toplumları ikna etmede kullanılan etkili bir araçtır. Medyanın insan tutum ve davranışları üzerindeki etkisi bilinmektedir. İletişim teknolojilerindeki hızlı değişim ve gelişim sunulan medya içeriğine de yansımıştır. Özellikle dijital içeriklerin tasarım, efektler, görüntü kalitesi vb. zenginleşmesi, farklılaşması, kişiye özel seçenekler sunulması, arttırılmış gerçeklik gibi uygulamalar insanların daha fazla mesajlara maruz kalmasına neden olmuştur.

İletişimde meydana gelen ve belki de bu denli artacağ tahmin edilemeyen değişim daha önce farkında olunmayan veya çoğunluğun bilmediği fikirlerin, tutumların ve hatta fobilerin yayılmasına neden olmuştur. Bunlardan en önemlilerinden biri de İslamofobidir.

Medya bu açıdan mesaj ya da 'enformasyon' değil; ideoloji üretmektedir (Golding ve Murdock, 1997, s.xvii). Derin tarihi kökleri bulunmasına rağmen, İslamofobinin artışındaki en önemli etkenlerden birinin medyada sunuş şekli olduğu söylenebilir. Elbette bunda medya sahipliği ve egemen medyanın da etkisi yadsinamaz (Poole, 2002; Jaspal ve Cinnirella, 2010; Steuter ve Wills, 2010). Murdock' in ifadesiyle “...sunulan çerçeveler zorunlu olarak onları üretenlerin çıkarlarına eklemlenmiştir" (Murdock ve Golding, 1974, s.226).

Her ürün, eser onu ortaya çıkaran yapımcısından izler taşır. Bu bir fikir, kitap, mimari eser, makale veya medya ürünü olabilir. İslamofobinin medyada temsilinde de bu izler görülmektedir. Araştırmalar medyanın İslami; barbar, şiddet, terör, gerici vb. tanımlamalarla verdiği, kamuoyunda da bu yönde algısal bir eğilim oluşturduğunu ve bu eğilimin de sürekli arttığını ifade etmektedir (Hafez, 2002, 2009; Poole, 2002; Schiffer, 2004, 2005; Deltombe, 2005, Halm, 2006; Frost; 2008, Glück, 2008; Schneiders, 2009; Leibold, 
2009; Bielefeldt, 2009, Ahmed ve Matthes, 2017; Khan ve Mythen, 2018). İslamin birçok kişi tarafından şiddet, militan, hoşgörüsüz, ve hatta tiranlıkla özdeşleşen geleneksel bir din gibi algılanmasında (Kalin, 2004) verilen bu mesajların etkisi büyüktür. Baudrillard'ın ifade ettiği gibi "Ana çizgileriyle demiryolunun 'ileti'si taşıdığı kömür ya da yolcular değil, yeni bir dünya görüşü, yerleşim alanlarının yeni statüsü vb.'dir. TV'nin iletisi aktardığı imgeler değil, dayattığı yeni ilişki ve algılama tarzları, ailenin ve topluluğun geleneksel yapılarının değişimidir" (Baudrillard, 2008).

Özellikle kültür endüstrisi bağlamında düşünüldüğünde İslamofobiyi bilinçli olarak çeşitli mesajlarla yaymak isteyen kişi veya kurumlar için popüler kültür çok etkili bir yol olarak görünmektedir. İlk kez Adorno ve Horkheimer' in bahsettiği ve "kapitalist endüstri ve meta estetiği tarafından soğrulan sanatın ve kültürün reddi, kültür metasının standardizasyon ve kitle üretimi tarafından yapay olarak farklılaştıılması" (Flew, 2002, s.9) olarak kavramlaşan kültür endüstrisi bugün birçok alanda etkisini göstermektedir. Hem küresel hem de yerel olarak etkili olan kültür endüstrileri, dünya genelinde büyük cirolar ve popüler kültür ikonları yaratmaktadır (Buchanan ve Partners, 2000, s.6). Bu açıdan popüler kültürün ürettiği islamofobik içerik ile tüketim düzeyi arasında diyalektik bir ilişkinin varlığında da söz edilebilir. "Üretim ve tüketim, diyalektik bir ilişki içinde var olur. Üretimin doğası ve yapısı, tüketimin doğası ve yapısını belirler ve tersi de geçerlidir" (Garnham, 2001, s.134).

Kültür endüstrisini besleyen ve yayılımını sağlayan en önemli faktör de medyadır. Medya islamofobik içerik üretmekte ve bunu tüketen kitlelerle karşılıklı olarak birbirlerini besleyerek sorunun artmasına neden olmaktadır. Medya bir yandan popüler ikonları tüm dünyaya tanıtmakta bir yandan da bireysel ve toplumsal algiyı şekillendirmektedir. Kültür endüstrisinin medya aracilı̆̆yla topluma sunduğu popüler karakterler, ikonlar, nesneler, imajlar, kurgusal öğeler, Adorno ve Horkheimer' in (1947) bahsettiği bir eğlence işletmesi gibi reklam ve tekrarlarla zihinlere kazınmaktadır. Bu durum medyanın baskın gücünü elinde tutan tarafın etkin kuşatmasını ve kuşatmanın farkında olmayan diğer tarafın da ikna olduğu bir sosyal kabulü beraberinde getirmektedir. Değişik bir dünya özlemi ve farklı bir insan arayışında olan modern kitle toplumu (Rabassierre, 1960, s.373), Frankfurt Okulu'nun öğretisinden hareketle gerçek bir kültürü değil kültür endüstrisinin sunduğu popüler kültür ürünlerini kabul etmektedir (Jay, 1989, s.312). 
Kitlenin bu kabul edişinde, popüler kültürün kurmaca karakterleri vasitasıyla oluşturdukları yapının izleyicinin düş görme ve fantazya gereksinimini karşılaması da yatar (Geraghty ve diğ. 1998, s. 65). Filmler, diziler ve oyunlar bunu gerçekleştirebilmenin etkili bir yoludur. Bireylere bu yolla verilen yeni bir öz kişiliğin (Mills, 1974, s.400) bir kaçış alanı yaratması, kurmaca bir dünyada sunulan hazır düşlerin varlığı (Frith, 1992) ve bireyin bunu sürdürme isteği bilişsel olarak kabulü ve iknayı hızlandırır. Bireydeki bu kabul içinde bulunduğu çevreyi ve toplumu da zamanla etkiler. Böylece Baudrillard'ın (2008) medya içeriğindeki gerçek iletinin aslında insan ilişkilerindeki yapısal değişime neden olduğu tespiti gerçekleşir. Sadece günlük yaşam pratiklerinde değil insanların bilişsel önyargiları, nefret, korku gibi duygularinda da etkili olur.

\section{Metodoloji}

Literatüre bakıldığında İslamofobi'yi değerlendirebilmek amacıyla geliştirilmiş olan ölçekler bulunmaktadır. Bunlardan biri de Lee ve ark. Tarafından geliştirilen İslamofobi Ölçeği (2009) olup, katılımcıların Müslümanların kaygılarına karşı duydukları olumsuz düşüncelerin derecesini değerlendirmek için kullanılmıştır. Fobinin ifade ettiği üzere ölçek, korkuyla ilgili ve kaçınılmamış dini önyargıya odaklanmış ve geçerli ve güvenilir bir ölçüm olduğu kanıtlanmıştır (Lee ve diğ., 2013).

Medya içeriklerinde nitel araştırma temelli yaklaşımın benimsendiği (Riffe ve diğ., 2005) bu çalışmada ise içerik analizi yöntemi (Cohen, 1963) kullanılmıştır. Neumann (2003, s.219) İçerik analizinde içerikten anlaşılması gerekenin iletilebilen kelimeler, anlamlar, olabileceği gibi resimler, semboller, fikirler, temalar veya mesajlar da olabileceğini belirtmiştir. Araştırmada kendisine özgü, daha önce karşılaşılmamış bir durum söz konusu olduğundan casestudy deseni (Yin, 2003) kullanılmıştır. Araştırmalarda bir ya da daha fazla durumu derinlemesine inceleyerek araştırmanın soru ve konularına dikkat çekmek amacıyla Durum çalışması kullanılır (Christensen ve diğ, 2015). Bireyler, gruplar, kurumlar, kültürler vb. durum olarak nitelendirilebileceği gibi kendisine has, özgün bir şey de durum olarak nitelendirilebilir (Patton, 1990). 
Görgül bir araştırma yöntemi olan durum çalışması, çok yönlü ve derinlemesine bir inceleme yapar (Yıldırım ve Şimşek, 2013; Patton, 1990). Çalışmada ele alınan tek durum içerisinde birden fazla alt analiz birimi (fotoğraf, video, metin) olduğundan iç içe geçmiş tek durum deseni kullanılmıştır (Yin, 2003).

\section{Verilerin Toplanması ve Analizi}

Çalışmanın amacı doğrultusunda "www.farkindayiz.gov.tr" web adresinde yer alan veriler iki araştırmacı tarafından birbirinden bağımsız olarak toplanmış ve analiz edilmiştir. İlk önce internet sitesinin içerisinde film, çizgi film, oyun ve müzik bölümlerinde yer alan (fotoğraf ve videolar) orijinal biçiminde araştırmacılar tarafından ayrı ayrı bilgisayarlara indirilmiştir. Sitede yer alan tüm açıklamalar ve diğer bilgiler de (word) dosyalarına kendi isimleri verilerek kaydedilmiştir. Toplamda 9 adet A4 sayfası (12 punto) metin dosyası oluşturulmuştur.

Tamamı Türkçe olan açiklamalardaki önemli kelimeler ve cümleler, Türkçe dilbilgisi ve anlam yapısı ile tekrarlanma durumu göz önüne alınarak belirlenmiştir. Veri toplanırken açıklamalarda, fotoğraf ve videolarda bazı yapımlara islamofobi ile alakalı olduklarından değil başka gerekçelerle yer verildiği görülmüştür. Örneğin; Türkiye'ye hakaret ('Friends' isimli dizide ingilizce yazılışı nedeniyle hindi göndermesi veya fes giyilmesi), Türk Bayrağına hakaret (The West Wing)veya Cumhurbaşkanı Recep Tayyip Erdoğan'a hakaret (War Dogs) gibi. Bu yapımlar veri kümesinden çıkarılmıştır. İslamofobik olduğu belirtilen yapımların ise fotoğrafları ve videoları ile sitede yapılan açıklamaları karşılaştırılarak devletin bahsettiği hakaret unsurlarının var olup/olmadığı kontrol edilmiştir. Eğer var ise fotoğraf ve videolarda bu unsurların nasıl kullanıldığına ilişkin her iki araştırmacı tarafından tanımlayıcı notlar alınmıştır.

Daha sonra iki araştırmacı tarafından birbirinden bağımsız olarak tüm veriler tekrar gözden geçirilmiş ve kategoriler haline getirilmiştir. Ardından araştırmacılar oluşturdukları bu kategorileri birbirleriyle karşılaştırmışlar ve nihai olarak 7 kategoride karar vermişlerdir. 
Tablo 1. Kategoriler

\begin{tabular}{llccccc}
\hline & Kategori & Film & Çizgi Film & Oyunlar & Müzik & Toplam \\
\hline 1 & Allah'a hakaret & - & - & 5 & - & 5 \\
2 & Peygamber Muhammed'e hakaret & 3 & 1 & 6 & - & 10 \\
3 & Kur'an-1 Kerim'e hakaret & 1 & 2 & 3 & - & 6 \\
4 & İslami sembollere saldırı & - & 2 & 8 & 2 & 12 \\
5 & İslam'ı terör ile ilişkilendirmek & 5 & 1 & 6 & - & 12 \\
6 & İslam'ı barbarlıkla ilişkilendirmek & 3 & - & - & - & 3 \\
7 & Politik aşırılık & 2 & - & 1 & - & 3 \\
\hline
\end{tabular}

\section{Bulgular}

Bu çalışma Türkiye devletinin medya içeriklerini islamofobik olarak değerlendirme kriterleriyle ilgili 3 ana tema bulmuştur:

1. İslami sembollere saldırı

2. Allah'a, Peygambere, Kur'an-1 Kerim'e hakaret

3. İslam-Terör ilişkilendirmesi.

\section{Tema 1: İslami sembollere saldır}

Mensching'e göre (1976, s.219-220) her şey sembol olabilir ama hiçbir şey kendiliğinden sembol olmaz. Bu açıdan baktığımızda herhangi bir şeyin sembol olabilmesi demek ona atfedilen bir değerin, önemin olduğunu gösterir. Bu değer ve önem zamanla kişide veya toplumda sembolle ilgili çağrışımların ve otomatik düşünce kalıpların oluşmasını sağlar. Dini bir sembol de işaret ettiği fenomenin düşünülmesini sağlar (Merrill, 1921).

Çoğunluğu Müslümanların yaşadığı Türkiye, aynı zamanda laik bir devlet yapısı olan ve demokrasi ile yönetilen bir cumhuriyettir. Türkiye'de yaşayan Müslümanların İslam'a bakış ve yaşayış şekli farklı yönetim biçimlerinin bulunduğu ve Müslümanların yoğun olarak yaşadığı diğer ülkelerden farklıdır. Bu durum sembollerin hakaret unsuru olarak kullanılmasına yönelik düşünce yapısını da etkiler. Örneğin Türkiye'de Müslüman kadınların türban takıp/takmamaları ile ilgili kararları tamamen kendilerine aittir ve bu konuda yasal bir zorunluluk bulunmamaktadır. Ayrıca halk arasında Müslüman bir kadına "Neden türban takmıyorsun?" şeklinde bir soru dahi “Özgürlüğüne müdahale ve saygisızlık" olarak değerlendirilmektedir. Diğer taraftan türban takmayı tercih eden bir kadının da bu durumdan dolayı günlük 
yaşantıda veya medyada aşağılanması "hakaret, özgürlüğe müdahale ve dine saygisızlık" olarak değerlendirilir. Herhangi bir dinin görevlisinin kıyafetinden dolayı aşağılanması da aynı şekilde değerlendirilmektedir.

Ayıca semboller saklanmış ve gizli anlamların aktarılmasına da izin verir (Issitt ve Main, 2014, s.19). Bu anlamlar tam olarak gözlemlenemese dahi olgu hakkında çok net olmayan bir duygu, his ve izlenim oluşturabilir (Foulquie, 1969, s.705).Internet sitesi www.farkindayiz.gov.tr adresinde yer alan ve açılamalardaki ifadelerde de sembol olarak değerlendirilen bazı yapımlar şunlardir:

\section{1- FamilyGuy Çizgi Dizi:}

Sitede çizgi diziyle ilgili açıklama şu şekildedir:“Dizinin 16. sezon 5. bölümünde "İstanbul'a büyük bir saldır düzenlenmesi" konu edilmektedir. Ayasofya'nın hedef alınıp Şehitler Köprüsü'nün yıkılı̧ı gösterilmektedir. Aynca bölümde tasvir edilen sokaklar İstanbul'u yansıtmamaktadır. Dizinin 11. sezon 15. bölümünde Müslüman karakter büyük bir terör eylemi düzenlemeye kalkışmaktadır."

Açıklamada sembolik olarak İstanbul, Ayasofya ve Şehitler Köprüsü vurgulanmakta ve Tema 3 'te incelenen İslam-Terör ilişkilendirmesine gönderme yapılmaktadır. İstanbul birçok dinin eserinin yer aldığı ve Osmanlı İmparatorluğu'nun başkenti olan bir şehirdir. Ayrıca İslam Peygamberi Hz. Muhammed'in "İstanbul mutlaka fethedilecektir. Onu fetheden komutan ne güzel komutan, onu feth eden asker ne güzel askerdir" (Çelebi, 1896) şeklindeki hadisinde de bahsi geçmektedir. Bu nedenle de dini bir önemi olan şehirdir. Ayasofya ise Fatih Sultan Mehmet tarafından 1453'te İstanbul fethedilinceye kadar kilise olarak kullanılmış ve bu tarihten sonra minareler eklenerek camiye çevrilmiştir. Şuan ise müze statüsündedir. Ayasofya'nın bu şekilde hedef alınması ve İstanbul'un terörist saldırının hedefi olarak gösterilmesi açılamada özellikle vurgulanmıştır. Ayrıca İstanbul sokaklarının gerçeği yansıtmadığı da eklenmiştir. 


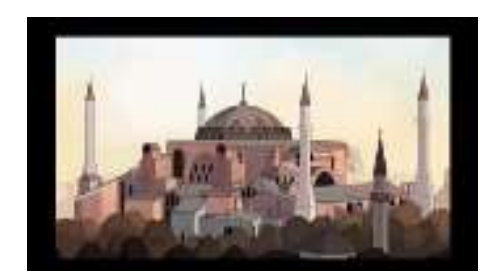

Resim 1. FamilyGuy çizgi dizisi Ayasofya Müzesi (www.farkindayiz.gov.tr)

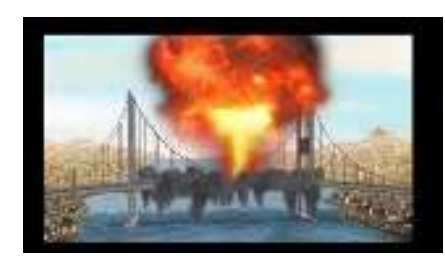

Resim 2.FamilyGuy Çizgi Dizi Şehitler Köprüsü (www.farkindayiz.gov.tr)

Şehitler Köprüsü'nün eski ismi Boğaziçi Köprüsü'dür. Fettullah Gülen Terör Örgütü (FETÖ) tarafından düzenlenen 15 Temmuz başarısız darbe girişimi ardından bu köprüde sivil halk ve polislerden 34 kişi öldürülmüştür. $\mathrm{Bu}$ tarihten sonra köprünün ismi 15 Temmuz Şehitler Köprüsü olarak değiştirilmiştir. Köprü Türk halkı açısından demokrasinin savunulduğu bir alan olarak görüldüğünden ayrı bir sembolik önemi vardır. Çizgi dizi bu sembollerin bir arada kullanıldığı ve terör ilişkilendirmesi nedeniyle seçilmiştir.

\section{Serious Sam Game:}

Sitede oyunla ilgili açıklama şu şekildedir:“Oyun, Dünya'yı istila eden uzaylılara karşı savaşma ve Dünya'yı kurtarma oyunudur. Oyunda; Hz. Ali'nin kabri üzerinde bulunan işleme ve yazıtlara kadar bire bir tasarlanmış olup, kabrin içerisinden yaratıklar çımaktadır."

Ali bin EbüTalib (Hazreti Ali), İslam Peygamberi Muhammed' in hem damadı hem de amcasıdır. Peygamber Muhammed'in ölümünün ardından yönetimi devralan dört halifenin sonuncusudur. Mezarı (Harem el-İmam Ali) Irak'ın Necef kentinde bulunmaktadır ve Şii Müslümanların kutsal yeridir.

Sembolik değeri oldukça yüksek olan bu türbe, oyunda birebir kopyalanmıştır. İnternet sitesi hem açıklamasında ve hem de oyundan alınan görüntülerin üzerinde Türkçe olarak bu durum belirtilmiştir. 


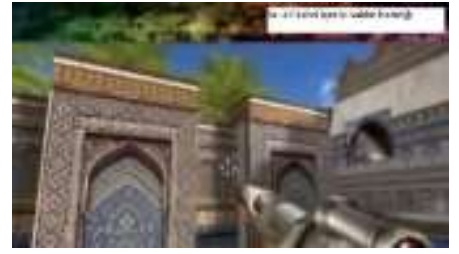

Resim 3. Serious Sam Game. Görüntü üzerindeki açıklamada "Hz. Ali'nin kabri içerisi saldırı hazırlığı" olduğu belirtiliyor. (www.farkindayiz.gov.tr)

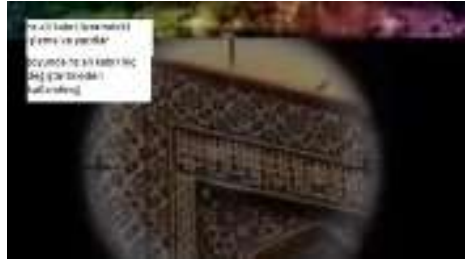

Resim 4.Serious Sam Game. Görüntï üzerindeki açıklamada $\mathrm{Hz}$. Ali'nin kabri ïzerindeki işleme ve yazttlar olduğu belirtilerek, oyunda hiç değiştirilmeden kullanıldığı belirtiliyor (www.farkindayiz.gov.tr).

\section{Devil May Cry 3 Game:}

Sitede oyunla ilgili açılama şu şekildedir:"Oyun, 3. şahıs ilerlemeli aksiyon oyunudur. Oyunda; Müslümanların kutsal evi olan Kâbe'nin kapısl, kötülü̈̆̈̈̈n ve şeytani türevlerin giriş kapısı olarak kullanılmaktadır."

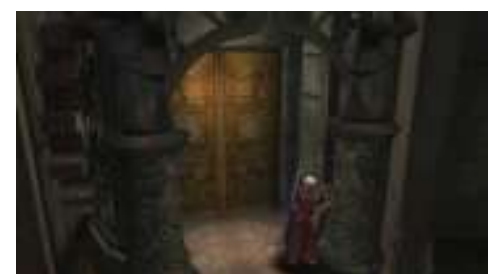

Resim 5. :Devil May CryGame. Oyunda kötülï̈̆̈̈̈ ve şeytani türevlerin giriş kapısı olarak kullanıldı̆̆ belirten sahnenin görüntüsï. (www.farkindayiz.gov.tr)

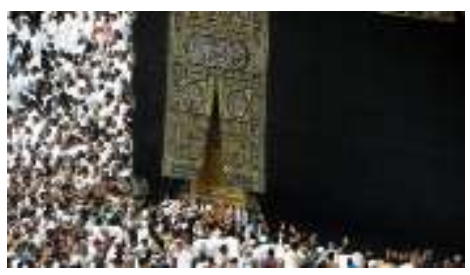

Resim 6. Kabe'nin giriş kapısı. Devil May CryGame oyunu açıklantrken oyundan altnan sahnenin yan sıra gerçek görüntü de konularak kıyaslama yapılması amaçlanmıştır. (wwww.farkindayiz.gov.tr)

\section{ResidentEvil 4}

Sitede oyunla ilgili açıklama şu şekildedir:"Oyun, 3. şahıs ilerlemeli aksiyon oyunudur. Oyunda; Peygamber Efendimizin (S.A.V.) kabrinin kapısı (Mescidi Nebevi), zombilerin karakterlere saldırmadan önceki büyük giriş kapısı olarak tasvir edilmiş."

Mescidi Nebevi, peygamber meclisi anlamina gelmektedir ve 622 yılında İslam peygamberi Muhammed ve sahabeler tarafından inşa edilmiştir. Me- 
dine'de bulunan bu alanda İslam peygamberi Muhammed'in kabri yer almaktadır (Ateş, 1994). Bu alanın giriş kapısı ise İslam âlemi tarafından oldukça iyi bilinmektedir. İnternet sitesinde oyunda bu kapının görselinin kullanıldığı, üzerine illuminati sembolünün yerleştirildiği ve oyunda zombilerin karakterlere saldırmadan önceki büyük giriş kapısı olarak tasvir edildiği belirtilmektedir.

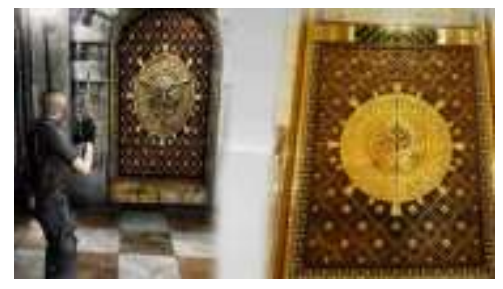

Resim 7. Solda ResidentEvil 4 Game oyunundan alınan görüntï ile sağda Mescidi Nebevi Giriş Kapısının gerçek görüntüsü konulmuştur (www.farkindayiz.gov.tr).

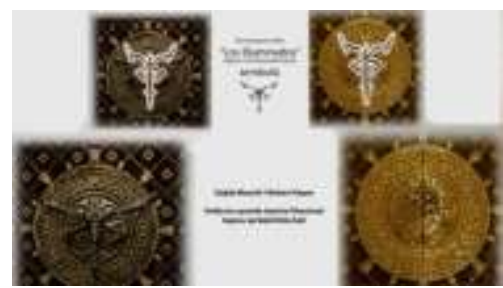

Resim 8. Görselde karşılaştırma yapılmıştır. Görselin üst kısmında "Oyunda geçen adıyla 'Los Illuminados' İnilizce (The Illuminated Ones) sembolü" kullanıldiğ dir. Görselin alt kısmında ise "Sağda Mescid-i Nebevi Kapisı. Solda ise oyunda üzerine Illuminati logosu yerleştirilmiş hali" denmektedir. (www.farkindayiz.gov.tr)

Oyunda Mescid-i Nebevi'nin giriş kapısına ait görüntülerin birebir alınarak kullanıldığı görülmektedir.

\section{Minarett Attack}

Sitede oyunla ilgili açıklama şu şekildedir: “İsviçre'de geliştirildi. Ülkedeki minare refarandumu öncesinde piyasaya çıtı. Aşırı sağcı politikacılar tarafından piyasaya sürüldü. Minareleri bombalayarak patlatma üzerine kuruludur. Minare üzerinde sakall ve fesli müezzinler tasvir edilmiştir.

ISVIÇRE'de minarelerin yasaklanması için 29 Kasım'da yapılacak referandum öncesi minare karşıtları bir de internette "Minareye saldırı" oyunu başlatması tepkilere yol açtı. Oyunu başlatan aşırı sağcı politikacı "Ama müezzine ateş edilmiyor" diye kendini savundu. ISVIÇRE'de minare inşaatlarının yasaklanması konusunda 29 Kasım'da yapılacak referandum öncesi kampanyaların sürdüren minare karşıtları, internete koyduklarn "Minareye saldirn" oyunuyla büyük tepki çektiler. "Minarett Attack" adlı oyunda amaç minarelerin yükselmesini ve müezzinin ezan okumasın 
engellemek. Bunun için müezzinin üzerine gidilip dü̈̆meye basıllyor. İsviçre halkın minare yapımına karşı harekete geçirmeyi hedefleyen oyununun mimarn ise, başında aşırn sağcı İsviçre Halk Partili (SVP) WalterWobmann'mn bulunduğu inisiyatif. Wobmann gelen eleştirileri değerlendirirken "Oyunda müezzine ateş edilmiyor, sadece bir "Stop" işareti çıkıyor" dedi.

Ürkütücü kampanya Oyunun sonunda "İsviçre minarelerle doldu. Bunun olmaması için 29 Kasım'daki referanduma katılın ve minare yasağına "evet" oyu verin" çağrısı yapılıyor. İsviçre geçtiğimiz haftalarda yine SVP partisinin başlattı̆̆ı minare karşıtı afiş kampanyası ile gündeme gelmişti. Afişlerin birinde, tesüttürlü bir kadın füzeleri çă̆rıştıracak ş̧ekilde çizilmiş minarelerle bezenmiş İsviçre bayrağının önünde resmediliyor. Afişlerle ilgili bir açıklama yapan Birleşmiş Milletler İnsan Hakları Komisyonu "Ürkütücü bir kampanya" yorumunda bulunmuştu.

Karşı oy verin Isviçre'de yapılan son kamuoyu yoklamalarma göre halkın yüzde 51'i minare yapımına karşı değil ve referandumda "Hayır" oyu verecek. Verilen bilgiye göre halkın sadece yüzde 35'i minare yapımına karşı. Ülkedeki dini cemaatler, aşırı să̆gclarm isteğinin aksine yasağa karşı oy vermeye çağırdılar. İsviçre İslam $\mathrm{Fe}$ derasyonu Çatı Birliği Başkanı HishamMaizar"İnsanları aşă̆ılayan iğrenç bir oyun" derken Irkçılığa Karşı Birlik (EKR) Başkanı GeorgKreis "Savcılık ve mahkemeler bu gelişmelere son vermeli" çağrısında bulundu. Ancak gelen tepkilere rağmen dün oyun hala internette oynanabiliyordu. (Hürriyet Avrupa).

İsviçre'de İslam karşıtlı̆̆ bilgisayar oyunlarına da yansıdı. Oyunda yerden mantar gibi biten minareler ve ezan okuyan müezzinler vuruluyor. Oyunda puan almak için, yerden mantar gibi biten devasa minarelerin şerefelerinde beliren müezzinleri vurmak gerekiyor. Aksi takdirde sürekli ezan okuyorlar. Oyun, aşırı sağcı kesimi memnun etmiş görünüyor. İnternet forumlarnda, "10 bin puan aldım. Şahane! Hayallerim nihayet gerçek oluyor. Mükemmel bir oyun! Bizim kronik alıngan Müslümanlarmı da mükemmel bulur mu acaba?" yorumlan dikkat çekiyor. Oyunu deneyenlerin bazılarn ise tedirgin: "Daha ne kadar aptal olmak gerekiyor ki; bu oyunla bizi eleştirenlerin eline koz veriyoruz. Bu, hareketimizin işine gelmez." 29 Kasım'da yapılacak 'minare referandumu' için hazırlıklarımı yoğunlaştıran Minare Karşıtı İnisiyatifi, İsviçre' yi ikiye bölen ırkçı afişlerden sonra bir adım daha atarak internet sayfası üzerinden saldırıların sürdürüyor. Ülkede minare yasağı konulması için bu çalısmaya imza atan hareket, bir internet sitesine yerleştirdiği oyunla minareyi hedef gösteriyor.

Oyunun başlangıcinda huzurlu bir coğrafya göze çarpıyor. Karlı yüksek dağlardan birinin üzerinde İsviçre bayrağı dalgalanıyor. Dağların hemen önünde kiliseleriyle 
sakin bir İsviçre şehri. Ancak 'başlat' komutunu verir vermez yerden şehri işgal edecek biçimde minareler yükseliyor. Bundan sonrası oyunu oynayana kalıyor. Ne kadar minare ya da müezzin vurursa o kadar puan alyyor. Vurulamayan müezzinler, oyunu kaybetmiş olmanin bir getirisi olarak durmadan ezan okuyorlar.

Oyunun arkasında ise afiş faaliyetlerinde olduğu gibi İsviçre Parlamentosu'nda en çok milletvekili bulunduran aşırı să̆cı İsviçre Halk Partisi (SVP) görülü̈yor. İnisiyatif Komitesi Başkanı WalterWobmann, aynı zamanda İsviçre Milli Meclisi'nde bir milletvekili.

SVP'nin bir önceki afiş propagandast ise eleştirilere rağmen Zürih ve Luzern şehirlerinin sokaklarında boy gösteriyor. Söz konusu afişlerde ön planda peçeli bir kadtnın resmedildiği afişlerin arka planında füze şeklindeki minarelerin, zemini oluşturan İsviçre bayrağın yırtarak yükseldikleri görülï̈yor.

Zürih şehri, afişleri İslam'ı olumsuz, tehdit edici ve tehlikeli göstermesi sebebiyle gerçeğe uygun görmese de, 'düşünce özgürlü̆̆̈̈' kapsammda kabul ettiğini açıklarken, Winterthur, Luzern, Cenevre ve St.Gallen de bu yönde hareket etti. Freiburg, Basel, Lozan ve Yverdon'da ise söz konusu afişlerin kamu alanında asılması yasaklandr."

Minare, Arapça "Nur" kelimesinden türetilmiş olup, "aydınlatan, ışık saçan yer" anlamına gelmektedir (Kamiloğlu, 2010). Minareler İslam kültürünün en eski sembollerinden biri olmuştur. Minare günde 5 vakit namaz k1lınması için ezan çağrısının yapıldığı yerlerdir. İslamın ilk zamanlarında Müslümanların sayısı az olduğu için ibadete (namaza) evlerin kapısı tek tek vurularak çağırılmışlar, ancak sonradan İslam Peygamberi Muhammed'in talimatıyla ilk ezan Bilal-i Habeşi tarafından yüksek bir evin çatısından okunmuştur (Berki ve Keskinoğlu, 1974). Daha sonraları minareler bu çağrıların yapıldığı caminin bir parçası, İslam dininin sembollerinden biri haline gelmiştir.

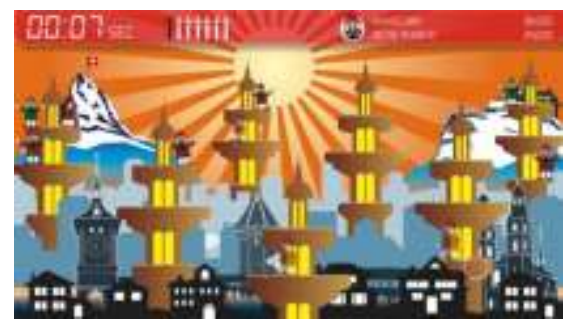

Resim 9. Oyunda arka planda İsviçre bayră̆ı ve dă̆ sembolü gözükmektedir. Ön planda ise minareler ve İslam din görevlileri görülmektedir (www.farkindayiz.gov.tr). 


\section{My Soul}

Sitede müzik klibiyle ilgili açıklama şu şekilde verilmiştir:“Tataristan'ın ünlü şarkıcılarından RezedaGaniullina, My Soul (Ruhum) isimli şarkı albümü için çektiğ $i$ video klipte; sanatçı Tataristan'daki Beyaz Cami'yi arkasına alarak dansöz kıyafetleri içerisinde dans etmektedir."

Yukarıda minarelerle ilgili yaptığımız incelemeyle aynı şekilde bu oyunda da Müslümanların ibadethanesi olan camiinin ve minarelerin kullanıldığı görülmektedir. Camiler tıpkı diğer dinlerin ibadethaneleri gibi saygı gösterilmesi gereken yerlerdir. İslam dininde cami veya diğer namaz kilınan yerlerde bedenin açık olmaması ve giyilen kıyafetlerin temiz ve özenle seçilmesi gerekir. Ayrıca camilerde müzik yayını ve dans vb. gösteriler yer almamaktadır.

İncelenen klipte ise bu durumun tam tersi görülmektedir. Çekim yapılan alanda Tataristan'daki Beyaz Camii görünmekte ve dansöz kıyafetleri ile müzik eşliğinde dans edilmektedir.

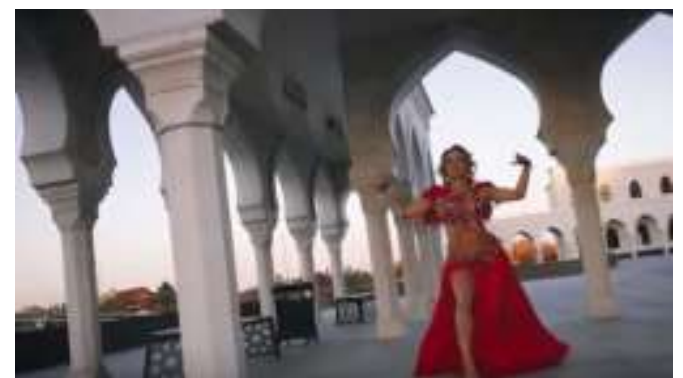

Resim 10. Tataristanlı ünlü şarkıcı RezedaGaniullina'nın My Soul isimli şarkısının klibinden bir kare (www.farkindayiz.gov.tr).

Tema 2: Allah'a, Peygamber Muhammed'e, Kur'an-ı Kerim'e hakaret

\section{Innocence of Muslims}

Sitede filmle ilgili açıklama şu şekildedir:" $A B D$ yapımı filmde Peygamber Efendimiz (SAV) öldürmekten zevk alan erkeklerden oluşan bir ayak takımının kanl lideri olarak lanse edilmekte ve Müslümanlar da actmasız, barbar ve terörist olarak gösterilmektedir." 
Medyada da yer alan ve protestolara neden olan bu filmle ilgili değerlendirmeler ve tartışmalar hala sürmektedir (Bulmer ve Solomos, 2018; Jamalet ve diğ., 2015). Misır kökenli Amerikalı yönetmen Nakoula Basseley tarafından çekilen film, Müslümanlardan büyük tepki toplamıştır. Saldırgan bir eğilimin olduğu açıkça görülen film nedeniyle birçok olay yaşanmıştır (Marantz, 2012).

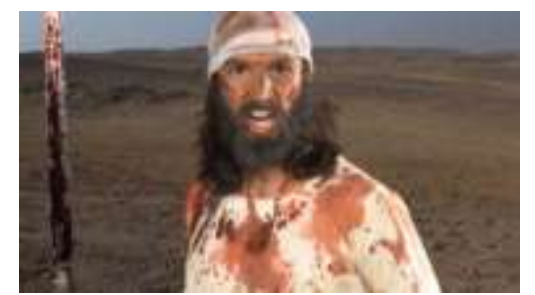

Resim 11. Innocence of Muslims isimli filmde İslam peygamberi Muhammed'in gösterildiği bir kare (www.farkindayiz.gov.tr).

\section{ResidentEvil 5}

Sitede oyunla ilgili açıklama şu şekildedir:“Oyun, 3. şahıs ilerlemeli aksiyon oyunudur. Türkiye listelerinde ilk 5, dünya sıralamasinda ilk 10 dadır. Şirketin yıllık kazancı 3 milyar dolara yakındır. Oyunda; sahnelerden biri kütüphanede geçmektedir. Kütüphanede "Kur'an-ı Kerim" hariç tüm kitaplar kitaplıktayken "Kur'an-ı Kerim" yerde bulunmaktadır."

İslam dininin uygulamalarına göre Kur'an-1 Kerim'in temiz ortamlarda bulunması ve belden yüksek bir seviyede tutulması gerekmektedir. Kur'an1 Kerim' in geleneksel olarak kullanılan kitap kapağı tasarımı vardır. Oyundaki kitabın kapak tasarımına bakıldığında Kur'an-1 Kerim olduğu Müslümanlar tarafından anlaşılmaktadır.

Açıklamadaki ifadeler oyunu yapan şirketin Türkiye ve Dünya sıralaması ile yıllık kazancı hakkında bilgiler verilmektedir. Bu bilgilerin verilmesi oyunun Türkiye'de ve Dünya'da birçok kişi tarafından oynandığını belirtmektir. Açıklamada kütüphanede geçen oyun sahnesinde diğer kitaplar raftayken Kur'an-1 Kerim'in yerde olduğu belirtilmektedir. Oyunun ilgili sahnesi incelendiğinde Kur'an-1 Kerim'in orijinal kapak tasarımının kullanıldığ̣ ve yerde olduğu gözükmektedir. 


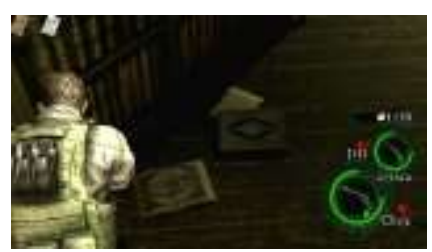

Resim 12. ResidentEvil 5 Game oyunundan alınan görüntü. Yerde Kur'an-ı Kerim'in olduğu gözükmektedir. (www.farkindayiz.gov.tr)

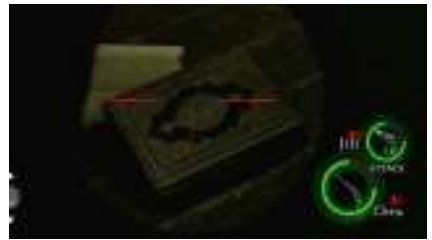

Resim 13: Resident Evil 5 Game oyunundan alınan görüntü. Yerde bulunan Kur'an-ı Kerim'e oyun içerisinde zoom yapıldığında geleneksel tasarım olduğu daha yakından görülmektedir. (www.farkindayiz.gov.tr)

\section{Tekken TagTournament}

Sitede oyunla ilgili açıklama şu şekildedir:“Oyun, değgişmeli modda (Tag) oynanan bir dövüş oyunudur. Oyunun Suudi Arabistan'daki sahnesinde dövüşçülerin yer aldığı sahne zemininde "Allah (C.C)" yazıları yazmaktadır. Müslümanlardan gelen yoğun tepkilerden sonra yapımcı firma 1.03 güncellemesiyle bu detayı kaldırdığım duyursa da oyunun son paketinde (DLC) hala gözükmektedir."

Açıklamada oyunda zeminde Allah yazısının bulunduğu ve yapımcı firmanın bunu kaldırdığını duyurmasına rağmen hala oyunda yer aldığı bilgisi özellikle vurgulanmaktadır.

İslam dininde Allah en güzel isimlerden biri olarak kabul edilir. Yine İslam dininde Allah'ın isimleri zemin veya pis yerlerde (Tuvalet, banyo, çöplük vs.) bulunması hoş karşılanmamaktadır. Aynı şekilde Kur'an-ı Kerim veya ayetler de bu tarzda yerlerde bulunmamalıdır. Bunun kasti olarak yapılması hakaret olarak kabul edilmektedir.

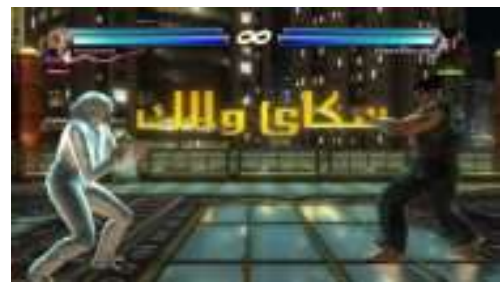

Resim 14. Tekken TagTournament Game oyunundan alınan görüntü (www.farkindayiz.gov.tr).

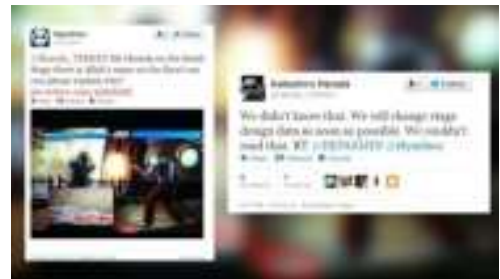

Resim 15. Sitede Tekken TagTournament oyunuyla ilgili tweeter ïzerinden verilen tepki ve yapımcı KatsuhiroHarada'nın verdiği cevap da yer almaktadır (www.farkindayiz.gov.tr). 


\section{South Park}

Sitede çizgi dizi ile ilgili açıklama şu şekildedir:“ABD yapımı çizgi dizinin 14. sezon 5. ve 6. bölümlerinde İslam dünyasının hassasiyetiyle dalga geçilerek Peygamber Efendimiz(SAV), oyuncak ayı kostümü giydirilmişşsekilde yansıtılmıştır. ABD yapımı çizgi dizinin 14. sezon 9. bölümünde intihar saldııısı düzenleyen teröristlerin kullandıkları uçakların kuyruklarında Türk bayrağı motifi kullanılmıştır."

Çizgi dizinin 14. sezon 5. ve 6. bölümlerde İslam peygamberi ayı kostümü giydirilmiş şekilde yansıtılmıştır. Müslümanların, İslam dini peygamberi Muhammed'in yüzü veya bedeninin tasvir edilmesiyle ilgili hassasiyeti tüm dünyada bilinmektedir. Buna rağmen çizgi dizide üst üste iki bölüm ayı kostümüyle verilmesi hakaret olarak kabul edilmiştir. Çizgi diziden alınarak internet sitesine konulan videoda da ilgili sahneler ek olarak verilmiştir. Sitede ayrıca dizinin 14. Sezon 9. bölümünde intihar saldırısı düzenleyen terörist uçakların kuyruk kısmında Türk Bayrağı motifini kullandığı da belirtilmiştir. Çizgi dizide bu hassasiyetlerin gözetilmediği açık bir şekilde görülmektedir.

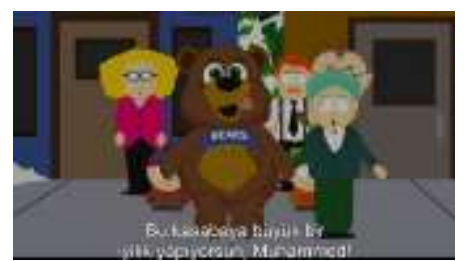

Resim 16. Sitede South Park çizgi diziden alınan görüntü. Altyazıda "Bu kasabaya büyük bir iyilik yapiyorsun, Muhammed" yazmaktadir (www.farkindayiz.gov.tr).

\section{Fireman Sam}

Sitede çizgi dizi ile ilgili açıklama şu şekildedir:"Çizgi filmin "Sorunlu Sular" başlıkl bölümünde, karakterlerden birinin Kur'an-ı Kerim'den bir sayfanın üzerine basarak düşmektedir. Üzerine basılan sayfa havada süzülürken, Mülk Suresi'nin 1326. ayetleri olduğu görülmüştür.

Yayıncı şirket sosyal medyada oluşan tepkiler üzerine Kur'an-ı Kerim'e hakaret olarak algılanan ilgili bölümü yayından kaldırmış, yapımo şirketler de konuyla ilgili soruşturma açılmasımı beklediklerini açıklamışlardır. 
Çizgi filmin fikir babası David Jones 2012 yılında Londra'da havaalanında Müslüman bir kadına başörtüsünü çıkarması yönünde yaptı̆̆g sözlü saldırıdan dolayı İslam karşıtlığı ile suçlanmıştır. İtfaiyeci Sam Türkiye'de de bazı çocuk kanallarında da yayınlanmıştır."

Açıklamada çizgi dizinin "Sorunlu Sular" başlıklı bölümünde karakterlerden birinin Kur'an-1 Kerim' den bir sayfanın üzerine bastığı ve daha sonra havada süzülürken gösterildiği belirtilmektedir. İlgili sahnenin ekran görüntüsüne de internet sitesinde yer verilmiştir.

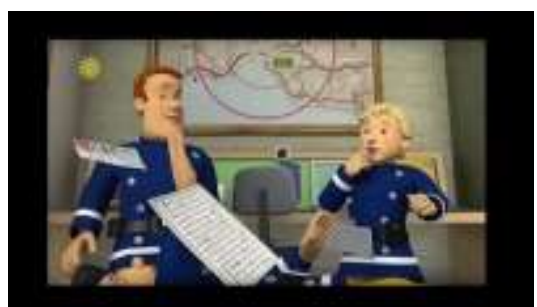

Resim 17. Fireman Sam çizgi dizisinin ilgili sahnesinden alınan görüntü (www.farkindayiz.gov.tr).

Yukarıda diğer maddelerde belirtildiği gibi Kur'an-1 Kerim, Müslümanlar tarafından Allah'ın sözü olarak kabul edilir. Ayetlerin yani Allah'ın sözlerinin yerde veya kirli, pis ortamlarda bulundurulması saygısızlık olarak kabul edilmektedir. Kur'an-1 Kerim Müslümanlar tarafından evlerin içinde de saygı göstergesi olarak yüksek yerlerde muhafaza edilir. Müslümanlar açısından aynı durum diğer dinlerin kitapları için de geçerlidir.
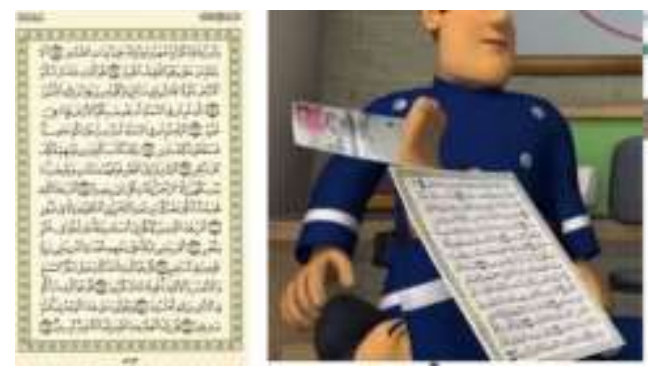

Resim 18. Fireman Sam çizgi dizisinin ilgili sahnesinden alınan görüntünün Kur'an-ı Kerim'deki Mülk Suresi ile karşılaştırılması (www.farkindayiz.gov.tr). 
İnternet sitesindeki açıklamada çizgi dizinin fikir babası olan David Jones'ın 2012 senesinde Londra'da Müslüman bir kadına başörtüsünü çıkarması yönünde sözlü saldırı yaptığı ve İslam karşıtlığı ile suçlandığı da ayrıca belirtilmiştir.

\section{Tema 3: İslam-Terör İlişkilendirmesi}

İnternet sitesi www.farkindayiz.gov.tr adresinde yer alan ve açılamalardaki ifadelerde İslam-Terör İlişkilendirilmesi olarak değerlendirilen bazı yapımlar şunlardır:

\section{Command Conquer Generals Zero Hour}

Sitede oyunla ilgili açıklama şu şekildedir:“Oyun, Command Conquer serisine ait bir strateji oyunudur. Oyunda; Amerika, Çin ve GLA olarak üç grup vardır. GLA, İslami terör teşkilatıdır. Diğer iki ülke normal ve modern teknolojilere sahip olarak resmedilirken, GLA adlı bu grup, canlı bomba saldırlar, suikastler, sabotajlar yapan, kimyevi silahlar kullanan intihar bombacilar olarak resmedilmektedir."

Açklamada oyunda yer alan 3 ülkeden ikisinin normal ve modern teknolojilere sahip olduğu resmedilirken, canlı bomba saldırıları, suikastler, sabotajlar yapan grubun İslami terör teşkilatı olarak yer aldığı bilgisi özellikle vurgulanmaktadır. Dolayısıyla oyunda İslam; terör saldırıları düzenleyen, masumları öldüren bir din ve İslam dinine mensup kişiler de terörist gibi gösterilmekte böylece İslam ve Terör arasında bir ilişkilendirme yapılmaktadır.

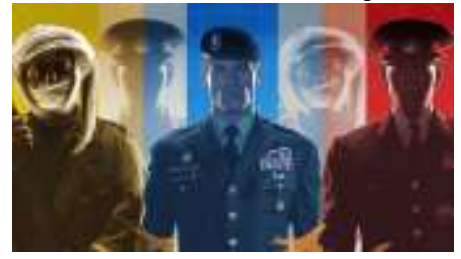

Resim 19. CommandConquerGenerals Zero Hour oyunundan alınan görüntü (wwww.farkindayiz.gov.tr).

\section{Counter Strike}

Sitede oyunla ilgili açıklama şu şekildedir:'Oyun, teröristler (Terrorists) ve terörle mücadele ekibi (Counter-Terrorists) olmak üzere iki takım olarak devreler 
halinde oynanmaktadır. Oyunda; Komandolar teröristleri öldürürken, teröristler "Allahuekber, Lailahe İllallah" şeklinde bağırmaktadır. Müslümanların yoğun tepkisi üzerine yapımo firma güncelleme yaparak bu ses efektlerini kaldırmıştır."

Açıklamada oyunda yer alan teröristlerin "Allahuekber, Lailahe İllallah" şeklinde bağırmaları oyunda teröristlerin İslam dinine mensup kişiler gibi gösterilerek, Müslümanların terörist olarak lanse edildiği görülmektedir. Dolayısıyla oyunda İslam terör saldırıları düzenleyen, masumları öldüren bir din, İslam dinine mensup kişiler de terörist gibi gösterilerek, İslam- terör ilişkilendirilmesine gönderme yapılmaktadır.

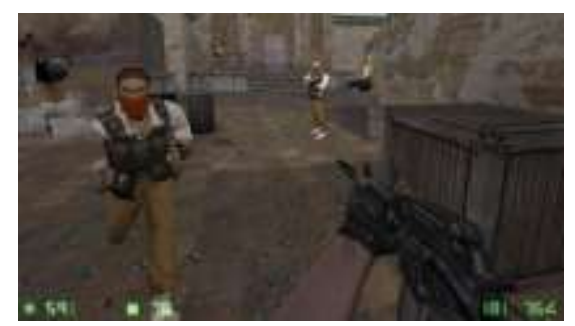

Resim 20: Counter Strike oyunundan alınan görüntü (wwww.farkindayiz.gov.tr).

\subsection{Saat: Bingazi'nin Gizli Askerleri}

Sitede film ile ilgili açıklama şu şekildedir: "2012 ABD yapımı filmdeön plandaki teröristlerden birine Türk bayraklı tişört giydirilmiş halde defalarca gösterilmektedir."

Açılamada teröristin Türk olarak lanse edildiğine dair bilgiye yer verildiği görülmektedir. İlgili sahnenin ekran görüntüsüne de internet sitesinde yer verilmiştir. Çoğunluğu Müslümanların yaşadığı Türkiye ve ülkede yaşayanlar terörist gibi gösterilerek, İslam- terör ilişkilendirilmesine gönderme yapıldığı görülmektedir.

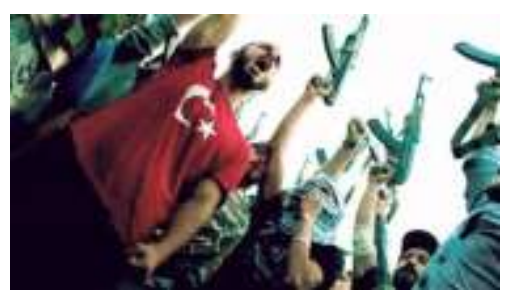

Resim 21. 13 Saat:Bingazi'nin Gizli Askerleri filminden alınan görüntü. Film görselinde en önde yer alan teröristin Türk Bayraklı tişört giydiği görülmektedir(wwww.farkindayiz.gov.tr). 


\section{Sacrificed Survivors The Untold Story Of The Ground Zero Mega Mosqoue}

Sitede film ile ilgili açıklama şu şekildedir:"Belgesel türündeki filmin afişinde ve DVD kapağında, İkiz Kuleler'in enkazı yakınında göndere çekilmiş Türk ve bazı Müslüman ülke bayraklarn görülmektedir. Afiş ve kapak üzerindeki resimler ile Müslüman ülkelerin 11 Eylül saldırılarmm faili olduğu algısı oluşturulmaktadır."

Açıklamada filmin afişinde ve dvd kapağında İkiz Kuleler'in enkazı yakınında göndere çekilmiş Türk ve Müslüman ülke bayraklarının bulunması ile belirli Müslüman ülkelerin 11 Eylül saldırılarının faili olduğu algısı oluşturulduğu ve dolayısıyla da İslam-terör ilişkilendirilmesi yapıldığının söz konusu olduğu görülmektedir.

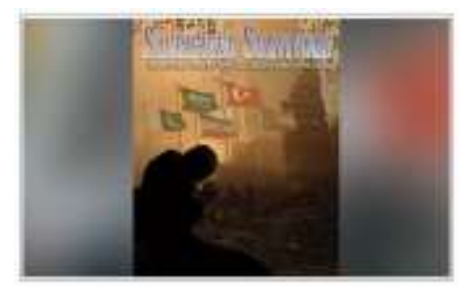

Resim 22.SacrificedSurvivorsTheUntoldStory Of TheGround Zero Mega Mosqoue filminin afişinden alınan görüntü (wwww.farkindayiz.gov.tr).

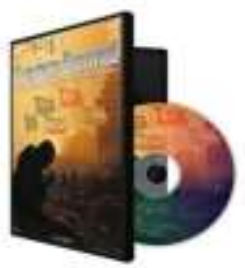

Resim 23.SacrificedSurvivorsTheUntoldStory Of TheGround Zero Mega Mosqoue filminin DVD kapağından alınan görüntü (www.farkindayiz.gov.tr).

\section{Sonuç}

Çalışma kapsamında medya içeriklerinin islamofobik olarak nitelendirilmesi için Türkiye'de devletin hangi kriterleri aradığ sorusu www.farkindayiz.gov.tr internet sitesi üzerinden araştırılmıştır. Araştırma sonuçlarına göre Türkiye devletinin medya içeriklerini islamofobik olarak değerlendirme kriterleri ile ilgili olarak; İslami sembollere saldırı, Allah'a, Peygambere, Kur'an1 Kerim'e hakaret ve İslam-terör ilişkilendirilmesi şeklinde 3 ana tema bulunmuştur.

Bu kapsamda 14 sinema filmi, 6 çizgi film, 29 dijital oyun ve 2 müzik olmak üzere toplam 51 yayın analiz edilmiş olup; inceleme sonucuna göre site- 
deki sinema filmi, çizgi film, dijital oyun ve müzik içeriklerinde, en fazla İslami sembollere saldırı ve İslam-terör ilişkilendirilmesi ile ilgili mesajların yer aldığı görülmüştür.

Medyanın insanları etkileyebilme, onların tutum ve davranışları üzerinde etki oluşturabilme durumu göz önüne alındığında; dijital oyun, çizgi dizi, film, müzik gibi yayınların içeriği ve sunuluş şekli olduça önemlidir. İslama ve Müslümanlara yönelik olumsuz bir algı oluşturacak şekilde mesajların bu içeriklerde yer almasının, islamofobiye yol açarak, toplumda Müslümanlara yönelik saldırgan düşünce ve tutumlarının ortaya çımasına sebep olabileceği düşünülebilir. Dolayısıyla da İslam dininin ve Müslümanların toplumlar tarafından saldırgan, hoşgörüden uzak, olumsuzluklar içeren bir din gibi algılanmasında medya aracılığı ile verilen bu mesajların etkisinin büyük olduğu söylenebilmektedir.

Bu noktada medya aracilığı ile islamofobiye yol açabilen bu durumu tersine çevirebilecek şekilde, İslam dini ve Müslümanlık ile ilgili gerçek ve doğru bilgilerin yer aldığı, olumsuz gerçekdışı algılamalara sebebiyet vermeyi engelleyebilecek, önyargısız yayınlar yapılabilmesinin önemi ortaya çıkmaktadır. Kamu kurumlarının iletişim araçları aracılığıyla toplumu İslamofobik yayınlar ve içerik hakkında bilgilendirmesinin gelecekte yararlı olacağı öngörülebilir. 


\section{EXTENDED ABSTRACT}

\section{Criteria For Evaluating Media Contents As Islamophobic: farkindayiz.gov.tr \\ Sefer Darıc1 - Zafer Özdemir \\ Sivas Cumhuriyet University - Beykoz University}

Islamophobia is a concept with deep historical roots (Lean and Esposito, 2012). The media also has a great role in the formation and spread of debates about Islamophobia. Many studies have investigated how islamophobia is represented in the media in different countries and the approach of the media to islamophobia (Allen, 2001; Cere, 2002; Perry and Poynting, 2006; Saeed, 2007; Gökçe, 2012; Zaal, 2012; Ansari, 2012; Awan, 2014; Ogan et al., 2014; Luqiu and Yang, 2018). It is important that the way the media presents Islamic symbols, lifestyles, and the difference between the east and west. Because the media is the leading actor in the culture industry. Media creates popular culture icons with movies, TV series, digital games, and other tools, and thanks to them, it spreads Islamophobia to a wider audience and places it in the mind.

A database was established by the Turkish government in June 2018 to combat Islamophobia. A lot of content that is found to be Islamophobic, from Hollywood movies to cartoons, from digital games to music, has been accessed via the official internet address "farkindayiz.gov.tr". On the website, a call text has been added to the public asking them to fight against islamophobic content and to report the content they noticed. Website created a perfect resource which is open to anyone who wants to learn the government approach of the to islamophobic criteria in to be secular country Turkey where is mostly inhabited by Muslims. In this study, the question of what criteria according to the government in Turkey were accepted to be Islamophobic media content was investigated through this website.

The most important factor that nourishes and spreads the culture industry is the media. The media also produce islamophobic content and the masses consuming this content and cause the problem to increase. The 
media, on the one hand, introduces popular icons to the world and on the other hand, shapes individual and social perceptions. The popular characters, icons, objects, images, fictional elements that the culture industry offers to the society through the media are engraved in the minds with advertisements and repetitions, such as an entertainment mentioned by Adorno and Horkheimer (1947). This situation brings with it an effective siege of the side that holds the dominant power of the media and social acceptance that the other party who is not aware of the siege is also convinced. The modern mass society (Rabassierre, 1960, p.373), who is looking for a different world longing and seeking a different person, accepts not the real culture but the popular culture products offered by the culture industry (Jay, 1989, p.312).

In this research, which used a single intertwined case pattern, the photographs, videos, and descrip-tions on the website were subjected to comparative content analysis. The results that criteria for evalu-ating media contents as islamophobic are grouped into three main themes:

1 - Attack on Islamic symbols.

2- Insulting Allah, the Prophet Muhammed, and the Holy Quran.

3-To associate Islam with Terrorism

In the scope of the study, the official website "farkindayiz.gov.tr" was examined by two researchers independently. A total of 51 publications, 14 of which are movies, 6 of cartoons, 29 of which are digital games and 2 of which are music, have been analyzed. According to the results of the analysis, it is seen that there are islamophobic messages in the contents such as movies, cartoons, digital games, and music.

Considering the power of the media to affect people and to influence their attitudes and behaviors; The content and manner of publications such as digital games, cartoons, movies, and music are very important. The messages given in a way that will create a negative perception of the religion of Islam and Muslims can lead to the emergence of aggressive thoughts and attitudes towards Muslims in society.

In addition, this situation causes the religion of Islam and Muslims to be thought offensive, free from tolerance and even associated with terrorism. It can be said that the effects of these messages given through the media are huge. 
At this point, it is clear that the perception of Islamophobia should be reversed in the media and that true and correct information about Islam and Islam should be included. The importance of making publications without prejudice, which may prevent negative and unrealistic perceptions, becomes apparent. It can be predicted that it will be beneficial in the future for public institutions to inform the society about islamophobic publications and content through communication tools.

\section{Kaynakça / References}

Ahmed, S. ve Matthes, J. (2017). 2000'den 2015'e kadar Müslümanların ve İslam'ın medya temsili: Bir meta-analiz. Uluslararası İletişim Gazetesi, 79(3), 219244.

Allen, C. (2001). Islamophobia in the media since September 11th. Exploring Islamophobia: Deepening our understanding of Islam and Muslims.University of Westminster, 29.

Ansari, H. (2012). From the far right to the mainstream: Islamophobia in party politics and the media. Campus Verlag.

Awan, I. (2014). Islamophobia and Twitter: A typology of online hate against Muslims on social media. Policy \& Internet, 6(2), 133-150.

Baudrillard, J., Deliceçaylı, H., ve Keskin, F. (2008). Tüketim toplumu. AyrıntıYayınları.

Berki, A. H., ve Keskioğlu, O. (1974). Hatem'ül Enbiya Hz. Muhammed ve Hayatı. Şehir ve Yayınevi.

Beydoun, K. A. (2016). Islamophobia: Toward a legal definition and framework. Colum. L. Rev. Online, 116-108.

Bielefeldt, H. (2010). Das Islambild in Deutschland In Islamfeindlichkeit (p.173206).VS Verlag für Sozial wissenschaften.

Bulmer, M.,ve Solomos, J. (2018). Innocence of muslims. Muslims, Migration and Citizenship içinde (s. 19-19).Routledge.

Cere, R. (2002). Islamophobia and the media in Italy. Feminist Media Studies, 2(1), 133-136.

Christensen, L. B., Johnson, B., ve Turner, L. A. (2015). Araşttrma yöntemleri: Desen ve analiz. Anı Yayıncilı.

Çelebi, E. (1896). Seyahatname, 10 vols. Istanbul: Ikdam Matbaasi [vols. 1-6], Devlet Matbaasi [vols. 7, 9, and 10], Orhaniye Matbaasi 8, 1896-1938.

Deltombe, T. (2005).L'islamimaginaire: la construction médiatique de l'islamophobieen France, 1975-2005. Paris. 
Foulquié, P. (1969). Dictionnaire de la langue philosophique. Paris.

Frost, D. (2008). Islamophobia: Examining causal links between the media and "race hate" from "below". International Journal of Sociology and Social Policy, 28(11/12), 564-578.

Garnham, N. (2001). Bir kültürel materyalizm teorisine doğru. Praksis, 4, 126-143.

Glück, A. (2007). Terror im Kopf: Terrorismusberichterstattung in der deutschen und arabischen Elitepresse. (Vol. 14). Frank \&Timme GmbH.

Golding, P., ve Murdock, G. (1997). Introduction: Communication and capitalism. The political economy of the media, 1 .

Gökçe, O. (2012). Avrupa medyasının ve kamuoyunun İslam algısı: İslamofobi, kolektif bir korkunun anatomisi. Sempozyum Tebliğleri, Ankara, 77-95.

Haddad, Y., ve Harb, N. (2014). Post-9/11: making Islam an American religion. Religions, 5(2), 477-501.

Hafez, K. (2002). Die politische Dimension der Auslands berichterstattung (Vol. 2). Baden-Baden: Nomos.

Hafez, K. (2009). Mediengesellschaft-Wissensgesellschaft?.In Islamfeindlichkeit (p. 99-117).VS Verlag für Sozial wissenschaften.

Halm, D. (2006).Zur Wahrnehmung des Islams und zursozio-kulturellenTeilhabe der Muslime in Deutschland. Essen.

Issitt, M., ve Main, C. (2014). Hidden religion: The greatest mysteries and symbols of the world's religious beliefs: The greatest mysteries and symbols of the world's religious beliefs. ABC-CLIO.

Jamal, A. A., Keohane, R. O., Romney, D., ve Tingley, D. (2015). Anti-Americanism and anti-interventionism in Arabic Twitter discourses. Perspectives on Politics, 13(1), 55-73.

Jaspal, R., ve Cinnirella, M. (2010).Media representations of British Muslims and hybridised threats to identity. Contemporary Islam, 4(3), 289-310.

Kalin, I. (2004). Roots of misconception: Euro-American perceptions of Islam before and after September 11. Islam, fundamentalism, and the betrayal of tradition, 143-187.

Kalmar, I., ve Ramadan, T. (2016). Anti-Semitism and Islamophobia (p. 351-372). London: Routledge.

Kayaoğlu, T. (2012). Three takes on Islamophobia. International Sociology. 27, 609615.

Keyman, E. Fuat (2002). Globalleşme, oryantalizm ve öteki Sorunu: 11 Eylül sonrası dünya ve adalet. Doğu Batı Düşünce Dergisi, 4 (20), 11-32. 
Khan, F., ve Mythen, G. (2018). Culture, media and everyday practices: Unveiling and challenging islamophobia. In Media, Crime and Racism (p. 93-115). Palgrave Macmillan, Cham.

Lean, N. C., Esposito, J. L., ve Shaheen, J. G. (2012). The Islamophobia industry: How the right manufactures fear of Muslims. London: Pluto Press.

Lee, S. A., Gibbons, J. A., Thompson, J. M., ve Timani, H. S. (2009). The Islamophobia scale: Instrument development and initial validation. The International. Journal for the Psychology of Religion, 19(2), 92-105.

Lee, S. A., Reid, C. A., Short, S. D., Gibbons, J. A., Yeh, R., ve Campbell, M. L. (2013). Fear of Muslims: Psychometric evaluation of the Islamophobia Scale. Psychology of Religion and Spirituality, 5(3), 157.

Leibold, J. (2009). Fremdenfeindlichkeit und Islamophobie.In Islamfeindlichkeit (p. 145-154).VS Verlag für Sozial wissenschaften.

Luqiu, L. R., ve Yang, F. (2018). Islamophobia in China: news coverage, stereotypes, and Chinese Muslims' perceptions of themselves and Islam. Asian Journal of Communication, 28(6), 598-619.

Marantz, A. (2012). The innocence of Muslims: Viral video gone wrong. The New Yorker.

Meer, N. (2014). Islamophobia and postcolonialism: continuity, Orientalism and Muslim consciousness. Patterns of Prejudice, 48(5), 500-515.

Mensching, G. (1976). Structures and patterns of religion.(Trans. H. F. Klimkeit und V. Srinivasa Sarma).Motilal Banarsidass Publ.

Merill, E. T. (1921). Mathews, S., ve Smith, G. B. (Eds.). A dictionary of religion and ethics. Macmillan. London.

Murdock, G., ve Golding, P. (1973).For a political economy of mass communications.Socialist register, 10(10), 205-234.

Neumann, W. (2003). Social research methods: Qualitative and quantitative approaches. Boston: Allynand Bacon.

Ogan, C.,Willnat, L., Pennington, R., ve Bashir, M. (2014). The rise of anti-Muslim prejudice: Media and Islamophobia in Europe and the United States. International Communication Gazette, 76(1), 27-46.

Patton, M. Q. (1990). Qualitative evaluation and research methods. SAGE Publications, Inc.

Perry, B., ve Poynting, S. (2006, December). Inspiring islamophobia: media and state targeting of Muslims in Canada since 9/11. In TASA Conference 2006, University of Western Australia \& Murdoch University, 4-7 December 2006 ASA 2006. 
Poole, E. (2002). Reporting Islam: Media representations and British Muslims.IB Tauris. Saeed, A. (2007). Media, racism and Islamophobia: The representation of Islamand Muslims in the media. Sociology Compass, 1(2), 443-462.

Said, E. W. (1979).Orientalism. New York: Vintage.

Said, E. W. (1985). Orientalism reconsidered. Race \& class, 27(2), 1-15.

Schiffer, S. (2004). Die Darstellung des Islams in der Presse. Sprache, bilder, suggestionen. EineAuswahl von techniken und beispielen.Würzburg.

Schiffer, S. (2005).Der Islam in deutschen Medien. AusPolitik und Zeitgeschichte, 20(2005), 23-30.

Schneiders, T. G. (2009). Islamfeindlichkeit. Wenn die Grenzen der Kritikverschwimmen. Wiesbaden (VS).

Sheehi S. (2011). Islamophobia: The Ideological campaign against Muslims. Atlanta, GA: Clarity Press, 2011.

Steuter, E., ve Wills, D. (2010). The vermin have struck again: Dehumanizing the enemy in post 9/11 media representations. Media, War $\mathcal{E}$ Conflict, 3(2), 152-167.

Trein, L. (2017). Islamophobia reconsidered: Approaching emotions, affects, and historical layers of orientalism in the study of religion. MethodETheory in the Study of Religion, 29(3), 205-220.

Vakil, A. (2009). Is the Islam in Islamophobia the same as the Islam in anti-Islam; or, when is it Islamophobia time?.e-cadernos ces, 3(3).

Yıldırım, A., ve Şimşek, H. (2013).Sosyal bilimlerde nitel araştırma yöntemleri.(9. GenişletilmişBaskı) Ankara: SeçkinYayınevi.

Yin, R. K. (2003). Case study research: Design and methods (Vol. 5). Thousand Oaks, CA: Sage.

Zaal, M. (2012).Islamophobia in classrooms, media, and politics. Journal of Adolescent $\mathcal{E}$ Adult Literacy, 55(6), 555-558.

Zebiri, K. (2008). There deployment of Orientalist themes in contemporary Islamophobia. Studies in contemporary Islam, 10(1-2), 4-44.

\section{Kaynakça Bilgisi / Citation Information}

Darıcı, S. ve Özdemir, Z. (2020). Medya içeriklerinin islamofobik olarak değerlendirilme kriterleri: farkindayiz.gov.tr. OPUS-Uluslararası Toplum Araştırmaları Dergisi, 15(23), 2079-2108. DOI: 10.26466/opus.587279 